\title{
Analysis of the Influence of Three Industrial Sectors' Investments on Yunnan's GDP
}

\author{
Liujie Tang* \\ Economics School \\ Yunnan University of Finance and Economics \\ Kunming, China \\ yyw1101@163.com
}

\author{
Hongming Zhang \\ Economics School \\ Yunnan University of Finance and Economics \\ Kunming, China \\ 84183991@qq.com
}

\author{
Hongxiang Luo \\ Economics School \\ Yunnan University of Finance and Economics \\ Kunming, China \\ 514267709@qq.com
}

\begin{abstract}
To change the economic backwardness as soon as possible, Yunnan Province in China has promoted its industrial structure. The paper selected economic indicators of Yunnan's GDP and the three industrial sectors' investments from 1978 to 2015 as the variables, and conducted the ADF test, Granger causality test and co-integration test. Then the VAR model was established to empirically analyze the impact of the three industrial sectors' investments on Yunnan's GDP. On this basis, it got the conclusion that it should invest further in the secondary and tertiary industries.
\end{abstract}

Keywords-China; Yunnan; Three Industrial Sectors; Investment

\section{INTRODUCTION}

Yunnan Province is located in the southwest of China, being an important radiation center for China to open up to the Southeast Asia. It also has important geographical advantages. With China's economy entering a new normal state, Yunnan's economic growth has slowed as expectation. It is proved by many economic growth theories that investment has long been the prime driver of economic growth [1-3]. Therefore, Yunnan invests a large number of public infrastructure projects. From 2012 to 2016, the average annual growth rate of investments in fixed assets has reached $21.4 \%$, higher than the national average growth rate of $6.7 \%$ over the same period. Moreover, Yunnan's fixed asset investments in the three industrial sectors i.e., agriculture, industry and service have been booming.

As to the investment structure, the investments in the three industrial sectors all increased steadily. Over the past few decades, the changes of investment structure in Yunnan have been in line with the Petty-Clark theorem [4]. The average growth rate of investment was the biggest in the tertiary industry, while being the smallest in the primary industry. Moreover, in recent years, the investment in the tertiary industry has surpassed the primary and secondary industries. To further explore the three industrial sectors' investments, this paper uses statistics and econometric methods to analyze the impact of the investments in the three industrial sectors on GDP, which would provide some references to the investment direction and policy formulation. Thus, Yunnan can adjust the investments in the three industrial sectors better and promote the economic development further.

In terms of the three industrial sectors, Chen Jing (2016) argued that the contribution of the primary industry to economic growth had gradually weakened while that of the tertiary industry to economic growth had gradually increased. This was the result of the industrial structure upgrading. In short term, there was no obvious correlation between industrial structure upgrading and economic growth. Nevertheless, in the long run, there existed mutual causality between economic growth and industrial structure upgrading [5]. Wang Lun (2017) concluded that the investments in the three industrial sectors all played roles in boosting economic growth. However, the economic upgrading promoted by the primary industry investment was already at a saturation state. Therefore, the secondary and tertiary industries were new sources of economic growth. Compared with the primary industry, the secondary and tertiary industry had more powerful and lasting effects on the economic growth [6]. In terms of investment, Lin Yifu (2014) did not agree that China's economic growth needed shift from investment-oriented to consumption-oriented. Although consumption was important, it would spend people's saving and increase debt. Debt accumulation could lead to crisis. Therefore, to improve investment efficiency was necessary [7].

In terms of research methods, Li Guangxi (2017) adopted the VAR model to study the industrial structure transformation in Hubei Province. By using impulse response function and variance decomposition, he analyzed the internal relations and mutual influences among the three industrial sectors in Hubei. The sensitivities of each industry to external shocks were figured out, which provided a good reference for analyzing the impact of the three industrial sectors' investments in Yunnan [8]. Tan Xin [9] and Zhao Xintao [10] (2016) analyzed the 
influence of industrial structure adjustment to economic growth in Yunnan by using statistical description, impulse response analysis and variance decomposition analysis. The results showed that the adjustment of industrial structure was an important factor for the steady economic growth.

A number of conclusions have been drawn from the studies on the three industrial sectors. The critical consensus is that industrial structure upgrading can effectively improve the overall output, productivity, fiscal revenue, employment rate and so on. For Yunnan Province, the government has also introduced a series of measures and enhanced supporting efforts to promote the investments in the three industrial sectors. The above researches looked the three industrial sectors as a whole, and came to the generally accepted view that it had good potential for development. However, the specific impact of the three industrial sectors' investments on the overall economy respectively had not been elaborated. Through the study of the three industrial sectors' investments, the basic connection with economic growth can be more clearly reflected. Since the three industrial sectors have their own characteristics and investment efficiency, it is necessary to study their own contribution to overall economy.

All in all, with the economy development, exploring the status quo and investment direction of the three industrial sectors in Yunnan is of great significance to understand the economic growth.

\section{STATUS QUO}

\section{A. The Three Industrial Sectors' investments of Yunnan}

The development process of the three industrial sectors in Yunnan was in line with the theory of the evolution of industrial structure. After the reform and opening up in 1978, the three industrial sectors recovered and investments started to increase. The three industrial sectors' investments in 1978 were 33, 569 and 302 million yuan respectively. By 1992, the 14th CPC National Congress had made the decision to speed up economic development and established a socialist market economy system for further reforms. Since then, the investments in the three industrial sectors have started to increase rapidly from 1992 to 2003. The investments of three industrial sectors was 483, 4966 and 8,620 million yuan respectively in 1992, with rapidly increasing to 3.88, 26.08 and 72.17 billion Yuan in 2003. Due to the unique historical culture and natural scenery advantages, the tourism industry as a part of the tertiary industry had greatly supported and contributed to Yunnan's economic development. As a result, the investment in the tertiary industry surpassed other two industries rapidly. By 2015, the investment in the three industrial sectors has reached 71.89, 314.59 and 920.46 billion Yuan (TABLE I).

TABLE I. THREE INDUST RIAL SECTORS' INVESTMENTS IN YUNNAN (2002-2015, BILLION YUAN)

\begin{tabular}{|c|c|c|c|c|c|c|c|}
\hline Year & $\mathbf{2 0 0 2}$ & $\mathbf{2 0 0 3}$ & $\mathbf{2 0 0 4}$ & $\mathbf{2 0 0 5}$ & $\mathbf{2 0 0 6}$ & $\mathbf{2 0 0 7}$ & $\mathbf{2 0 0 8}$ \\
\hline Primary & 3.80 & 3.88 & 4.22 & 5.29 & 6.53 & 7.22 & 17.40 \\
\hline Secondary & 21.12 & 26.08 & 42.37 & 65.32 & 79.85 & 99.75 & 125.90 \\
\hline Tertiary & 57.94 & 72.17 & 86.47 & 104.92 & 135.66 & 172.92 & 127.42 \\
\hline Year & $\mathbf{2 0 0 9}$ & $\mathbf{2 0 1 0}$ & $\mathbf{2 0 1 1}$ & $\mathbf{2 0 1 2}$ & $\mathbf{2 0 1 3}$ & $\mathbf{2 0 1 4}$ & $\mathbf{2 0 1 5}$ \\
\hline Primary & 19.71 & 17.68 & 15.32 & 14.31 & 25.09 & 44.10 & 71.89 \\
\hline Secondary & 152.49 & 177.26 & 431.84 & 253.02 & 286.88 & 278.88 & 314.59 \\
\hline Tertiary & 187.66 & 357.93 & 171.37 & 488.02 & 650.21 & 784.40 & 920.46 \\
\hline
\end{tabular}

\section{B. The Change of GDP in Yunnan}

The trend of Yunnan's GDP (TABLE II) has been in a steady upward trend for a long time. The trend shows a similar form of monotonically increasing "exponential function", fully demonstrating that Yunnan's economy has developed faster with great potential over the past few decades. Combined with the trend of the three industrial sectors' investments, it can be clearly observed that the investment trend is similar to the trend of GDP. In macroeconomic theory, the three industrial sectors' investments not only affect each other but also affect GDP. Therefore, the existing theories have laid a solid foundation to analyze the impact of the three industrial sectors' investments on GDP.

TABLE II. GDP GROWTH IN YUNNAN (2002-2015，BILLION YUAN)

\begin{tabular}{|c|c|c|c|c|c|c|c|}
\hline Year & $\mathbf{2 0 0 2}$ & $\mathbf{2 0 0 3}$ & $\mathbf{2 0 0 4}$ & $\mathbf{2 0 0 5}$ & $\mathbf{2 0 0 6}$ & $\mathbf{2 0 0 7}$ & $\mathbf{2 0 0 8}$ \\
\hline GDP & 231.3 & 255.6 & 308.2 & 346.3 & 398.8 & 477.3 & 569.2 \\
\hline $\begin{array}{l}\text { Growth } \\
\text { Rate (\%) }\end{array}$ & 8.2 & 10.5 & 20.6 & 12.4 & 15.2 & 19.7 & 19.3 \\
\hline Year & $\mathbf{2 0 0 9}$ & $\mathbf{2 0 1 0}$ & $\mathbf{2 0 1 1}$ & $\mathbf{2 0 1 2}$ & $\mathbf{2 0 1 3}$ & $\mathbf{2 0 1 4}$ & $\mathbf{2 0 1 5}$ \\
\hline GDP & 617.0 & 722.4 & 889.3 & $1,030.9$ & $1,183.2$ & $1,281.5$ & $1,361.9$ \\
\hline $\begin{array}{l}\text { Growth } \\
\text { Rate (\%) }\end{array}$ & 8.4 & 17.1 & 23.1 & 15.9 & 14.8 & 8.3 & 6.3 \\
\hline
\end{tabular}

\section{EMPIRICAL ANALYSIS}

\section{A. Selection of Variables and Sources of Data}

The original data used in this study are mainly from "Yunnan Statistical Yearbook" (National Bureau of Statistics, from 1978 to 2015).

In order to stabilize the data and weaken the impact of the trend, three endogenous variables were designed, i.e., the logarithm of Yunnan's GDP ( $g d p)$, primary industry investment (prin), secondary industry investment (sein) and tertiary industry investment (tein) ( TABLE III) .

TABLE III. VARIABLE SET

\begin{tabular}{|c|c|c|c|c|}
\hline Variable & Description & Maximum & Minimum & Average \\
\hline Ingdp & $\begin{array}{c}\text { The logarithmof Yunnan's } \\
\text { GDP }\end{array}$ & 9.519234 & 4.234831 & 6.983042 \\
\hline Inprin & $\begin{array}{c}\text { The logarithm of primary } \\
\text { industry investment }\end{array}$ & 6.577694 & -1.108663 & 2.506184 \\
\hline Insein & $\begin{array}{c}\text { The logarithmof secondary } \\
\text { industry investment }\end{array}$ & 8.370650 & 1.738710 & 4.836693 \\
\hline Intein & $\begin{array}{c}\text { The logarithm of tertiary } \\
\text { industry investment }\end{array}$ & 9.127456 & 2.199444 & 5.453661 \\
\hline
\end{tabular}

\section{B. VAR Model}

To explain the relationship between the GDP and the three industrial sectors' investments, the study conducted the ADF unit root test, co-integration test, Granger causality test, model lag length test, short-term forecast, model stability test, impulse response function and variance decomposition in sequence.

\section{1) $A D F$ Test}

To ensure the data are stationary, the analysis conducted the ADF unit root test firstly. The Ingdp, Inprin, Insein, and Intein are all non-stationary.

In order to modify the model, the study takes first order difference for all variables and conducts the ADF unit root test 
again (TABLE IV). The test results show that all the variables are stationary after the first order difference process. Therefore, there might be some co-integration relationship among the variables.

\section{2) Co-integration Test}

To distinguish whether there is a co-integration relationship among the variables; Johansen co-integration test should be done. The test results show that there is only one co-integration relationship among the variables: Ingdp, Inprin, Insein, and Intein (TABLE V). In other words, there is no obvious longterm stable relationship among the variables. Thus, it should use the first order difference of the variables which are stationary to establish the model.

TABLE IV. ADF TEST RESULTS

\begin{tabular}{|c|c|c|}
\hline Variables & Prob. & Conclusions \\
\hline $\operatorname{lngdp}$ & 0.666 & Non-stationary \\
\hline$\Delta \operatorname{lng} d p$ & 0.048 & Stationary \\
\hline Inprin & 0.932 & Non-stationary \\
\hline$\Delta$ lnprin & 0.002 & Stationary \\
\hline Insein & 0.929 & Non-stationary \\
\hline Insein & 0.000 & Stationary \\
\hline Intein & 0.978 & Non-stationary \\
\hline$\Delta$ lntein & 0.000 & Stationary \\
\hline
\end{tabular}

TABLE V. JOHANSEN CO-INTEGRATION TEST RESULTS

\begin{tabular}{|c|c|c|c|}
\hline Null Hypothesis & Trace Statistic & Prob. & Conclusions \\
\hline None & 70.336 & 0.000 & Refuse \\
\hline At most 1 & 29.707 & 0.051 & Accept \\
\hline At most 2 & 10.755 & 0.227 & Accept \\
\hline At most 3 & 3.075 & 0.080 & Refuse \\
\hline
\end{tabular}

3) Granger Causal Test

To tell whether there exists a causal relationship among them, the Granger causal tests need to be done (TABLE VI).

TABLE VI. GRANGER TEST RESULTS

\begin{tabular}{|c|c|c|c|}
\hline Null Hypothesis & F-Stat & Prob & Conclusions \\
\hline$\Delta \operatorname{lnprin}$ does not Granger Cause $\Delta \operatorname{lng} g p$ & 5.651 & 0.008 & Refuse \\
\hline$\Delta$ lngdp does not Granger Cause $\Delta$ Inprin & 0.285 & 0.754 & Accept \\
\hline$\Delta \operatorname{lnsein}$ does not Granger Cause $\Delta \operatorname{lng} d p$ & 2.331 & 0.115 & Refuse \\
\hline$\Delta l n g d p$ does not Granger Cause $\Delta$ Insein & 2.412 & 0.107 & Refuse \\
\hline$\Delta l n t e i n$ does not Granger Cause $\Delta \operatorname{lng} d p$ & 0.330 & 0.721 & Accept \\
\hline$\Delta$ lngdp does not Granger Cause $\Delta$ Intein & 1.909 & 0.166 & Refuse \\
\hline$\Delta$ Insein does not Granger Cause $\Delta$ lnprin & 1.425 & 0.256 & Accept \\
\hline$\Delta l n p r i n$ does not Granger Cause $\Delta$ lnsein & 0.112 & 0.895 & Accept \\
\hline$\Delta$ lntein does not Granger Cause $\Delta \operatorname{lnprin}$ & 1.306 & 0.286 & Accept \\
\hline$\Delta$ Inprin does not Granger Cause $\Delta$ Intein & 1.121 & 0.339 & Accept \\
\hline$\Delta$ Intein does not Granger Cause $\Delta$ lnsein & 2.235 & 0.125 & Refuse \\
\hline$\Delta$ Insein does not Granger Cause $\Delta$ Intein & 2.319 & 0.116 & Refuse \\
\hline
\end{tabular}

Because of the small number of time series data, the results show these conclusions at the $20 \%$ level of significance test:

The investment in the primary industry will affect the GDP. In addition, there are interactions between secondary industry investment and GDP. Although the tertiary industry investment does not have a significant impact on the GDP, the GDP affects the tertiary industry investment.

There is no obvious causal relationship between the investment in primary industry and that in secondary industry. There is also no obvious causal relationship between the investment in primary industry and that in tertiary industry.
However, there is an interaction between the investment in secondary industry and tertiary industry.

\section{4) Lag Length Test}

Since there is no obvious co-integration relationship, the first-order difference of each variable is taken as the model's variable and the appropriate lag length should be tested (TABLE VII).

TABLE VII. MODEL LAg LENGTH TEST RESUlt S

\begin{tabular}{|c|c|c|c|c|c|}
\hline Lag Length & $\boldsymbol{L R}$ & $\boldsymbol{F P E}$ & $\boldsymbol{A I C}$ & $\boldsymbol{S C}$ & $\boldsymbol{H Q}$ \\
\hline 0 & NA & $7.45 \mathrm{E}-07$ & -2.759 & $-2.574^{*}$ & -2.698 \\
\hline 1 & 33.652 & $5.80 \mathrm{E}-07$ & -3.021 & -2.096 & -2.719 \\
\hline 2 & $30.715^{*}$ & $6.79 \mathrm{E}-07$ & -2.920 & -1.255 & -2.377 \\
\hline 3 & 20.497 & $4.03 \mathrm{E}-07$ & -3.594 & -1.189 & -2.810 \\
\hline 4 & 25.671 & $2.49 \mathrm{E}-07$ & -4.396 & -1.250 & -3.370 \\
\hline 5 & 13.430 & $3.44 \mathrm{E}-07$ & -4.706 & -0.821 & -3.440 \\
\hline 6 & 20.586 & $1.16 \mathrm{E}-07^{*}$ & $-7.105^{*}$ & -2.479 & $-5.597^{*}$ \\
\hline
\end{tabular}

It can be seen from TABLE VII that the LR statistic supports the second-order lag, while the FPE statistics, AIC and HQ all support the sixth-order lag. However, it has been verified that the model is not stable under the sixth-order lag, with sacrificing the degrees of freedom. Therefore, it considers second-order as the lag length of the model based on a comprehensive consideration.

\section{5) Model Setting}

Because the VAR model does not impose a zero constraint on the parameters, the estimated value of the parameter need not be removed and the model does not analyze the specific economic significance of each parameter. Therefore, the standard error and the t-Statistic are omitted, with the model expressed as follows (Eq. 1):

$$
\begin{aligned}
& {\left[\begin{array}{l}
\Delta \operatorname{lng} d_{p_{t}} \\
\Delta \operatorname{lnprin} t_{t}
\end{array}\right]\left[\begin{array}{c}
0.050792 \\
0.084509
\end{array}\right]} \\
& \left.\begin{array}{l}
\Delta \operatorname{lnprin}_{t} \\
\Delta \operatorname{lnsein}_{t}
\end{array}\right]=\left[\begin{array}{l}
0.050792 \\
0.084509 \\
0.173595
\end{array}\right] \\
& {\left[\begin{array}{l}
\Delta \operatorname{lnsein}_{t} \\
\Delta \operatorname{lnt}_{\text {ein }}
\end{array}\right]=\left[\begin{array}{c}
0.173595 \\
0.123784
\end{array}\right]} \\
& {\left[\begin{array}{llll}
0.619991 & -0.081305 & 0.015406 & 0.022761 \\
0.628821 & 0.230914 & -0.289153 & 0.13683
\end{array}\right]\left[\begin{array}{ll}
\Delta l n d p_{t-1} \\
\Delta l n s e i n_{t-1}
\end{array}\right]} \\
& +\left[\begin{array}{cccc}
0.619981 & -0.081305 & 0.015406 & 0.022761 \\
0.628821 & 0.230914 & -0.289153 & 0.136831 \\
1.165675 & -0.009013 & -0.031301 & 0.297787
\end{array}\right]\left[\begin{array}{l}
\Delta \ln g p_{t-1} \\
\Delta \text { lnprin }_{t-1} \\
\Delta \text { lnsein }_{t-1}
\end{array}\right] \\
& +\left[\begin{array}{cccc}
1.165675 & -0.009013 & -0.031301 & 0.297787 \\
-0.984982 & 0.170903 & 0.386009 & -0.467302
\end{array}\right]\left[\begin{array}{c}
\Delta \operatorname{lnsein}_{t-1} \\
\Delta \operatorname{lntein}_{t-1}
\end{array}\right]
\end{aligned}
$$

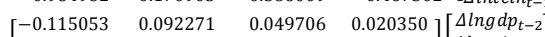

$$
\begin{aligned}
& +\left[\begin{array}{rrrr}
-0.053658 & -0.163090 & 0.110428 & 0.152992 \\
-1.951559 & 0.221671 & 0.115649 & 0.011457
\end{array}\right]\left[\begin{array}{l}
\Delta \operatorname{lnprin}_{t-2} \\
\Delta \operatorname{lnsein}_{t-2}
\end{array}\right]+\left[\begin{array}{c}
e_{1 t} \\
e_{2 t} \\
e_{3 t}
\end{array}\right] \text { (1) } \\
& {\left.\left[\begin{array}{cccc}
-1.951559 & 0.221671 & 0.115649 & 0.011457 \\
1.541707 & -0.000422 & 0.155363 & -0.309516
\end{array}\right]\right|_{\Delta \text { lntein }_{t-2}} ^{\Delta \sin _{t-2}}}
\end{aligned}
$$

\section{6) Short-term Forecasting}

Since there are no current period variables on the right side of the equation in the VAR model, it has advantage to use the model to predict the short-term value beyond the samples. According to the model, it can make the forecast of the Yunnan's GDP, primary industry investment, secondary industry investment and tertiary industry investment in 2016. Assign the variables (Eq. 2):

$$
\begin{aligned}
& \Delta \operatorname{lngdp}_{t-1}=0.060894 \Delta \operatorname{sinprin}_{t-1}=0.488695 \Delta \operatorname{sinsein}_{t-1}=0.120484 \\
& \Delta \text { lntein }_{t-1}=0.159947 \\
& \Delta \operatorname{lngdp}_{t-2}=0.079750 \quad \Delta \operatorname{lnprin}_{t-2}=0.564065 \Delta \operatorname{lnsein}_{t-2}=-0.028275 \\
& \text { Intein }_{t-2}=0.187623
\end{aligned}
$$

So the predictive value at 2016 can be derived that $g d p_{2016}=1,504.54$ (billion), $\operatorname{prin}_{2016}=83.69$ (billion), sein $_{2016}=404.88$ (billion) and e ein $_{2016}=1,101.26$ (billion) 


\section{7) Model Stability Test}

In addition to short-term forecasts, VAR model can also make impulse response function and variance decomposition to further analyze the impact. Thus, it should test the model stability firstly (Fig.1).

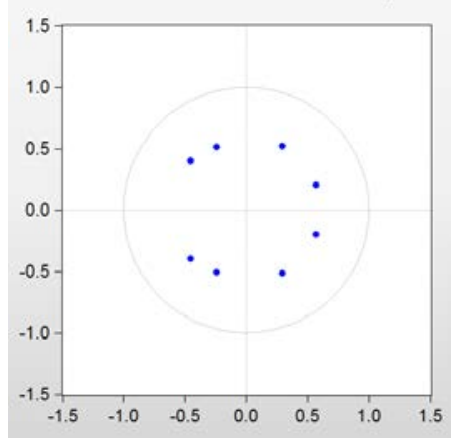

Fig. 1. Characteristic Root

Fig. 1 shows that the characteristic-roots are all located in the unit circle, so the model is stable.

8) Impulse Response Function

Thus, it can make impulse response function because of the model's stability (Figure2).
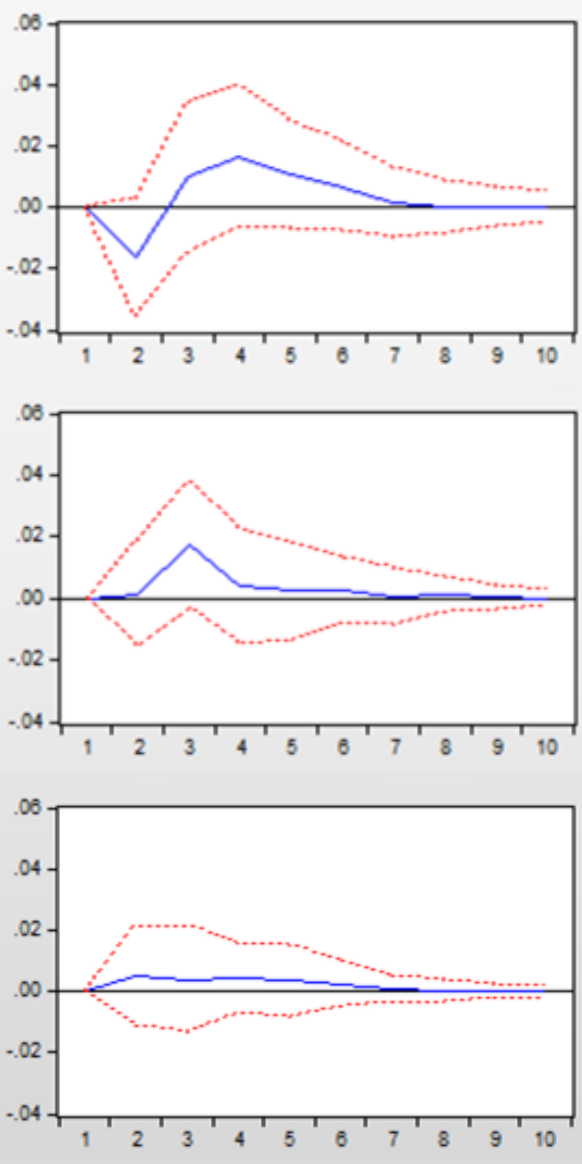

Fig. 2. $\Delta$ lnprinve, $\Delta$ Inseinve, $\Delta$ lnteinve Impulse Response Function
Fig.2 shows that the investment in primary industry has negative impact on the GDP growth rate in the 2nd period (year) but reach the peak of $1.673 \%$ in the 4 th period (year). The investment in secondary industry has impact on GDP growth rate to $1.737 \%$ at the peak of the 3rd period (year). Moreover, the impact from the investment in tertiary industry on GDP growth rate is relatively low, but it lasts a long time, and reaches the peak of $0.505 \%$ in the 2 nd period (year).

\section{9) Variance Decomposition}

Variance decomposition is to analyze the importance of structural shocks from different variables by analyzing the contribution of each structural shock to the change of endogenetic variables (usually measured by variance). TABLE VIII shows the variance decomposition of $\Delta$ Ingdp in different period.

TABLE VIII. VARIANCE DECOMPOSITION OF $\triangle$ LNGDP

\begin{tabular}{|c|c|c|c|c|c|}
\hline Period & Standard Error & $\Delta$ Ingdp & $\Delta$ Inprin & $\Delta$ Insein & $\Delta$ Intein \\
\hline 1 & 0.04794 & 100 & 0 & 0 & 0 \\
\hline 2 & 0.05850 & 91.386 & 8.571 & 0.033 & 0.010 \\
\hline 3 & 0.06517 & 83.328 & 7.660 & 8.154 & 0.858 \\
\hline 4 & 0.06884 & 78.410 & 10.799 & 8.070 & 2.720 \\
\hline 5 & 0.06979 & 76.414 & 11.928 & 8.161 & 3.496 \\
\hline 6 & 0.07020 & 75.559 & 12.329 & 8.285 & 3.827 \\
\hline
\end{tabular}

Ignoring the impact given by GDP itself, the contributions of the investment growth rates to the GDP growth rate are all stable in the 6th period (year). The three industrial sectors' investments accounts for $12.329 \%, 8.285 \%$ and $3.827 \%$ respectively.

\section{CONCLUSIONS}

Through the above theoretical and quantitative analysis, a qualitative fact can be clearly seen: the influence of Yunnan's primary and secondary industry investments on GDP is slightly higher than that of the tertiary industry investment. In the impulse response function, the impact of the primary industry investment on the GDP has three phases: descending and then rising, eventually tending to smooth. This is due to the innate features of the primary industry, which has a longer investment cycle. The impact of the secondary industry investment on the GDP reaches the peak in the third phase and then becomes stabilized. Moreover, the impact on the GDP from the tertiary industry investment is long lasting.

Combined with the above analysis and results, the primary industry has a relatively large impact on the fluctuation of GDP because of its inherent weakness, production efficiency constraints and long investment cycle. Thus, the investment efficiency should be improved to guarantee the investment effects, especially in agriculture technology and insurance. For the secondary industry, its investment has a large positive impact on the fluctuation of GDP. Therefore, it is necessary to expand investment including amount and areas. For the tertiary industry, despite its impact on GDP is relatively small, it will have a very long impact time. At the same time, Yunnan has inherent tourism advantages. Efficient investment in tourism can bring more benefits to Yunnan.

In short, in the coming years or even decades, the economic development in Yunnan will be improved further. While the secondary and tertiary industries will become the important 
forces to drive Yunnan's GDP growth. Using the secondary industry as the foundation and using the tertiary industry as the pioneer, can bring more economic development opportunities.

\section{ACKNOWLEDGMENT}

Thanks are due to Cooperative Innovation Center of Private Economy in Yunnan University of Finance and Economics for their collaboration and to Hualei Ma for data collecting.

\section{REFERENCES}

[1] Solow, Robert M. "A contribution to the theory of economic growth." The quarterly journal of economics 70.1 (1956): 65-94.

[2] Harrod, Roy F. "Scope and method of economics." The Economic Journal 48.191 (1938): 383-412.

[3] Domar, Evsey D. "Capital expansion, rate of growth, and employ ment." Econometrica, Journal of the Econometric Society (1946): 137-147.
[4] Clark, Colin. The conditions of economic progress. No. 04; HC55, C5 1951.

[5] Chen Jing. "Yunnan Industrial Structure and Economic Growth-Empirical Research Based on VAR Model”, Journal of Financial Economy, vol.6, 2016, pp. 76-78. (In Chinese)

[6] Wang Lun. "An Empirical Study of Three industrial sectors' investments and Economic Growth in China under the New Normal", Journal of Economy Forum, vol.9, 2017, pp. 9-12. (In Chinese)

[7] Lin Yifu. "Investment Is Still the Driving Force of China's Economic Growth”, Journal of Finance and Economics, vol.7, 2014, pp. 30-31. (In Chinese)

[8] Li Guang xi. "Research on Industrial Structure Transformation of Hubei Province Based on VAR Model", Journal of Statistics and Decision, vol.1, 2017, pp. 145-148. (In Chinese)

[9] Tan Xin, Zhao Xintao. "Influence of Industrial Structure Adjustment on the Stability of Economic Growth--Take Yunnan Province as an Example". Journal of Resource Development and Market, 2016, 32(05), pp. 573-577. (In Chinese)

[10] Lin Yifu. "Investment Is the Best Choice”, Journal of Shanghai State Capital, 2015(04), pp. 54-55. (In Chinese) 